Short Paper

\title{
Occurrence of Biogenic Amines at Different Processing Stages of Dried Herring
}

\author{
Satoru Suzuki, ${ }^{\dagger}$ Kentaro Kobayashi, and Kozo Takama ${ }^{\dagger, \dagger \dagger}$ \\ Faculty of Fisheries, Hokkaido University, Hakodate, Hokkaido 041, Japan \\ (Received October 12, 1993)
}

Key words: dried herring, biogenic amine, histamine, polyamine, processing

Although it is known that food poisoning by histamine occurs in dried mackerel and dried horse mackerel, ${ }^{1)}$ such incidents have not yet been reported in dried herring (Migaki-nishin, in Japanese). To reveal whether food poisoning amines are produced during the process of drying herring, we analyzed biogenic amines including histamine in herring samples.

Fresh herring Clupea pallasi was dried in a cold wind-dryer (Toyo Electric Drying Oven FSP 62, Toyo Seisakusho) at $15-20^{\circ} \mathrm{C}$ for 5 days. Five fish were sampled every day and analyzed. A $5 \mathrm{~g}$ sample of the herring muscle was homogenized in 4 times the volume of $10 \%$ trichloroacetic acid (TCA) with mortar. Extractable materials were collected as supernatants of centrifugation at $700 \times g$ (Kubota Rotor No. 3) for $20 \mathrm{~min}$. This extraction was repeated twice, and the sample solution was made up to $50 \mathrm{~m} l$ with $10 \%$ TCA solution. Biogenic amines were simultaneously analyzed by the HPLC method as previously reported, ${ }^{2)}$ while free amino acids were analyzed by the Hitachi-835 system.

The occurrences of biogenic amines such as putrescine, cadaverine, agmatine, spermidine, spermine and histamine are shown in Fig. 1. More putrescine and cadaverine was produced than of other amines, and peaked at 3 and 4 days,

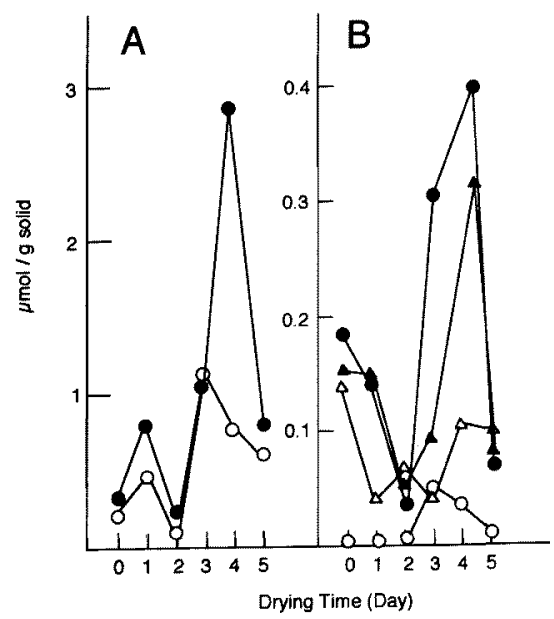

Fig. 1. Change in production of biogenic amines over time. Symbols in panel A: putrescine $(O)$ and cadaverine $(O)$; in panel B: agmatine $(O)$, spermine $(\Delta)$, spermidine $(\triangle)$, and histamine $(O)$. respectively. The maximum production of agmatine and spermine was observed at 4 days. The spermidine content remained almost constant throughout the drying period. Histamine was detected at 3 and 4 days, although the amount was only $0.04 \mu \mathrm{mol} / \mathrm{g}$ solid which is equivalent to $4.31 \mu \mathrm{g} / \mathrm{g}$ solid. It is worth noting that all the amines dramatically decreased at 5 days. Histamine poisoning occurs at $4 \mathrm{mg}$ of histamine $/ \mathrm{g}^{3)}$; in our experiments, the histamine level was less than this concentration. However, other amines especially cadaverine and agmatine can also lead to histamine poisoning. ${ }^{1{ }^{14)}}$ In this study, a significant amount of biogenic amines was not detected in the final product, suggesting that there is no risk of food poisoning by this product. However, the production of large quantities of cadaverine raises the risk of food poisoning by dried herring if the fish are not completely dried.

Needless to say, biogenic amines are formed from corresponding amino acids which are derived from protein; histidine, lysine and arginine are converted to histamine, cadaverine and agmatine, respectively. Amino acid analysis revealed that the free amino acid corresponding to each amine increased before amine production (Fig. 2). This indicates that a chain reaction of protein degradation occurs while processing fish meat, that is, proteins and/or peptides are converted to free amino acids, which are then converted

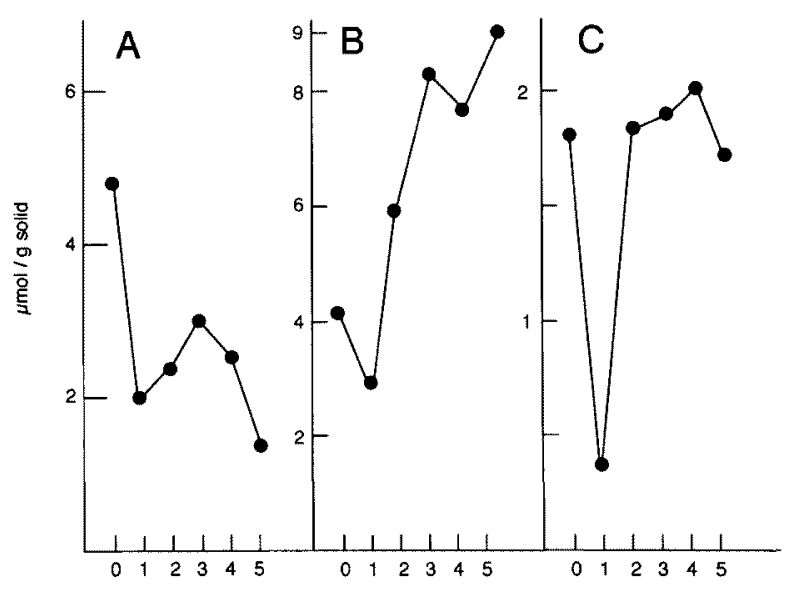

Fig. 2. Change in amount of amino acid over time. A: histidine, B: lysine, and C: arginine.

$\dagger$ Present address: Faculty of Agriculture, Kochi University, Nankoku, Kochi 783, Japan.

it Corresponding author. 
to amines.

A unique polyamine metabolism is known to occur in fish spoilage bacteria ${ }^{5,6)}$ and decomposing raw fish. ${ }^{7)}$ To assess the safety of fish products, the metabolism of biogenic amines must be studied further not only in raw fish but also in processed fish. We thank the Yamada Fisheries Research Center for kindly supplying herring samples.

\section{References}

1) S. L. Taylor: CRC Crit. Rev. Toxicol., 17, 91-128 (1987)
2) S. Suzuki, K. Kobayashi, J. Noda, T. Suzuki, and K. Takama: J. Chromatogr., 508, 225-228 (1990).

3) A. Yoshida and A. Nakamura: J. Food Hyg. Soc. Japan, 23, 339-343 (1982).

4) O. Arunlakshana, J. L. Mongar, and H. O. Oshild: J. Physiol., 123, 32-54 (1954).

5) Y. Matsui, K. Takama, and S. Suzuki: Biochem. Int., 18, 825-832 (1989)

6) S. Suzuki, A. Kubo, and K. Takama: J. Mar. Biotechnol., 1, 47-50 (1993)

7) H. Yamanaka, K. Shimakura, K. Shiomi, T. Kikuchi, and M. Okuzumi: J. Food Hyg. Soc. Japan, 30, 289-294 (1989) 